\title{
Neither Coral- nor Symbiont- Genetic Diversity may Explain the Resistance of the Coral Echinopora lamellosa to Bleaching
}

\author{
Imam Bachtiar ${ }^{1,2 *}$, Muhammad Irsyad Abiyusfi Ghafari ${ }^{3}$, Ibadur Rahman ${ }^{4}$, Baiq Hilda Astriana $^{4}$ \\ 1)Department of Mathematics and Science Education, FKIP, University of Mataram, Indonesia, 83125 \\ 2) Program Studi Magister Pendidikan IPA, Postgraduate Program, University of Mataram, Indonesia, 83125 \\ 3) Department of Biology, Postgraduate School, Hasanuddin University, Indonesia, 90245 \\ 4)Department of Marine Science, Faculty of Agriculture, University of Mataram, Indonesia, 83125 \\ * Corresponding author, email: imambachtiar@unram.ac.id
}

\begin{abstract}
Genetic diversity has an important role in the stability of coral populations in coping with disturbances. In the last three bleaching events, the coral Echinopora lamellosa survived better in the eastern- than the western- Lombok waters that are not related to algal symbiont diversity. The present study aimed to assess the genetic diversity of E. lamellosa from the two locations in the Lombok waters. The ITS1-5.8S-ITS2 (whole ITS region) marker was used to identify and to determine the genetic structure, genetic variation, and demographic pattern of E. lamellosa. The results showed that E. lamellosa of the two locations are two different populations. The haplotype diversity was very high indicating a predominance of sexual reproduction mode for both eastern and western populations. The phylogenetic topology suggests there is possible connectivity between populations, whereas the haplotype network exhibits a restricted gene flow between the two populations. The results suggest that the present E. lamellosa populations were from both surviving colonies and new recruitment of long-distance larvae. Both populations likely share the same larvae supply brought from source-reefs in the Flores Sea or Makassar Strait by the Indonesian Throughflow. The present and previous studies revealed that genetic diversity alone yet to explain the resistance of E. lamellosa in eastern and western Lombok waters.
\end{abstract}

Keywords: bleaching, larval dispersal, population, re-colonization, survivorship

\section{INTRODUCTION}

Genetic diversity has been recognized as one of the most important factors for any community in coping with disturbance. So far, studies on coral population genetic related to coral bleaching mostly focused on the diversity of coral's symbionts (Swain et al. 2021). Many studies showed that symbionts play an active role in determining the resistance of corals during bleaching events (e.g. Wall et al. 2020), however, the link between the resistant symbiont and the coral genetic diversity is obscure.

Genetic diversity is responsible for differences in the physiological responses of a coral population to environmental changes (Cooke et al. 2020). A coral population with a more diverse genotype will have more 
chances to survive from coral bleaching (Morikawa \& Palumbi 2019). Coral genetic diversity may support coral survivability from bleaching, by determining coral's capability in sorting the right symbiont (Peixoto et al. 2017), production of photopigment (Zamani et al. 2019; Wall et al. 2020), or production of heat shock protein (Fuller et al. 2020). Biological legacies that survive in the population after disturbance will secure population recovery from both sexual and asexual reproductions. Surviving corals can increase their chances by shifting symbiont to cope with the next bleaching event, a mechanism commonly known as the adaptive bleaching hypothesis (Buddemeier \& Fautin 1993).

Coral bleaching is one of the most threatening disturbances for coral reefs in the Anthropocene Epoch. During the last four decades, there have been four major bleaching events (severe bleaching), that severely caused global coral mortality in 1983, 1998, 2010, and 2016 (Brown \& Suharsono 1990; Hughes et al. 2018). The bleaching events occurred at increasingly shorter intervals, leaving an insufficient time for corals to recover. The shorter time interval between each bleaching phenomenon potentially causes successive effects that may lead to an accelerated mass extinction of marine life.

In the Lombok waters, coral communities experienced at least three major bleaching episodes, in 1998, 2010, and 2016 (Bachtiar \& Hadi 2019). During the three bleaching events, coral communities in the eastern population always survive, while the western population experienced severe mass coral mortality in many genera (Bachtiar 2001a; Bachtiar \& Hadi 2019). The differential bleaching impacts between coral communities in western and eastern Lombok waters yet to be explained solely from the symbiont diversity. The coral E. lamellosa in the eastern population host multiple clades $\mathrm{B}$ and $\mathrm{C}$, whereas those in the western population host only clade $\mathrm{C}$ (Bachtiar et al. 2019). Neither B nor $C$ clades are the thermally tolerant symbiont. Surviving corals of E. lamellosa in both western and eastern populations provide opportunities to test a hypothesis that there is an association between coral genetic diversity and its bleaching resistance. If resistance to coral bleaching is associated with coral genetic diversity, coral populations of eastern Lombok waters should have more diverse DNA than the western population. The present work is the first study on the coral genetic population of E. lamellosa in Indonesian waters.

\section{MATERIALS AND METHODS}

\section{Sample collection}

Colony samples of the coral Echinopora lamellosa were collected from a key of Gili Petagan in the north-west of Alas Strait (eastern Lombok waters, $8^{\circ} 26^{\prime} 1$ " $\mathrm{S}$ and $116^{\circ} 44^{\prime} 33^{\prime \prime} \mathrm{E}$ ) and a key of Gili Anyaran in the south-east of Lombok Strait (western Lombok waters, $8^{\circ} 43^{\prime} 16^{\prime \prime} \mathrm{S}$ and $115^{\circ} 54^{\prime} 50^{\prime \prime} \mathrm{E}$ ), as shown in Figure 1. Samples of E. lamellosa fragments at sizes of $2-3 \mathrm{~cm}^{2}$ were collected in a SCUBA diving at 5-7 meters depth. To prevent the possibility of sampling clones, only colonies of E. lamellosa with a distance of at least $3 \mathrm{~m}$ apart were sampled. Samples were then preserved in 95\% ethanol and stored at room temperature. The samples collected from the northwest Alas Strait are referred to as 'eastern populations' labeled with the 'GPE', while samples originated from Sekotong Bay (Lombok Strait) are referred to as 'western populations' labeled with 'SEL'.

\section{DNA extraction}

The genomic DNA was isolated from pulverized and sterilized E. lamellose samples by using the DNeasyTM Blood and Tissue Kit (Qiagen $\left.{ }^{\circledR}\right)$ as per 


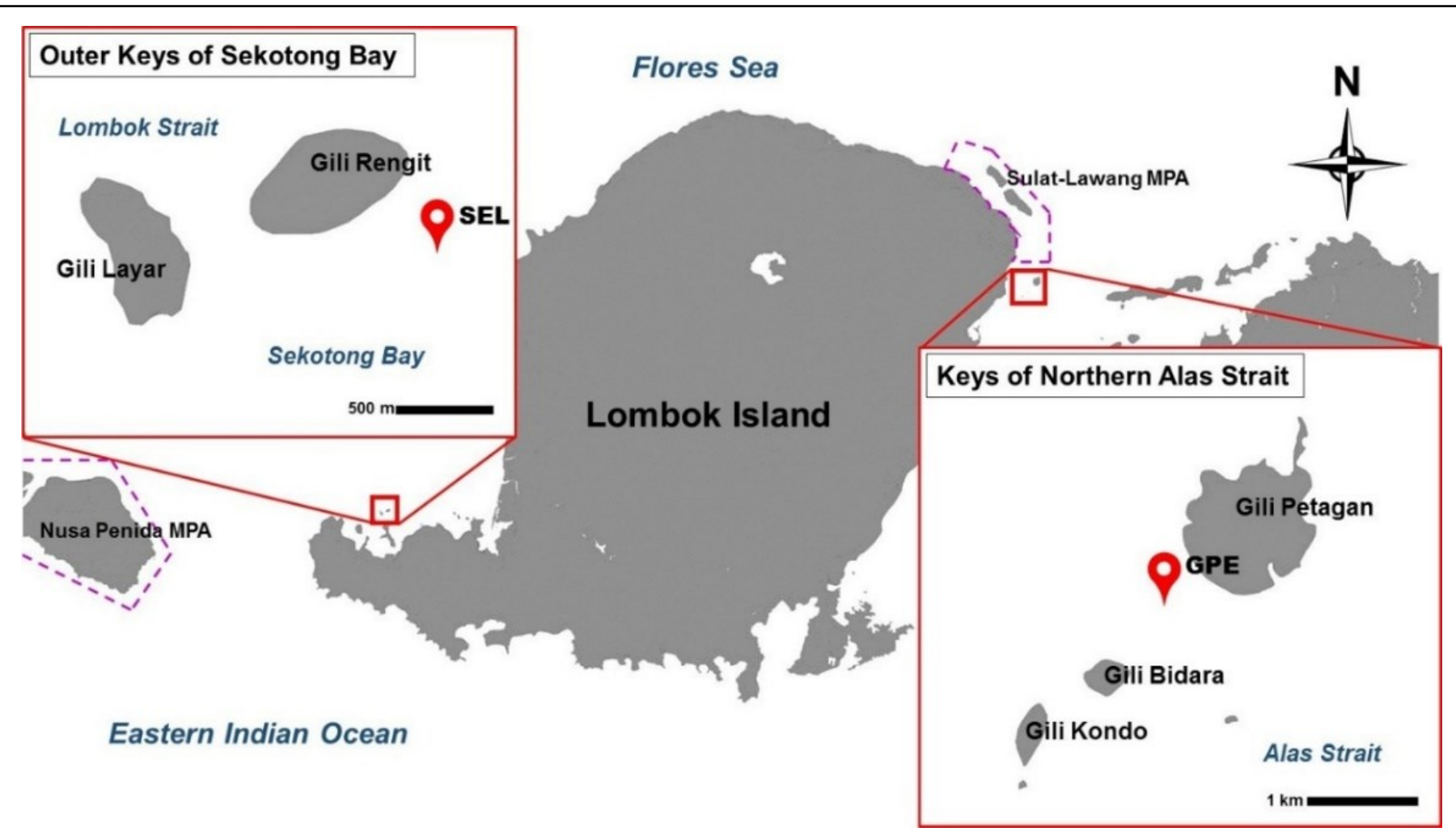

Figure 1. Sampling locations (SEL and GPE) of the study. The distance between the two locations is approximately 97 $\mathrm{km}$.

manufacturer instruction (Qiagen ${ }^{\circledR}$ manufacturer protocol for extracting DNA of tissue and blood) with 12 hours pre-incubation. The DNA of coral was separated from the DNA of the symbiont through multilevel centrifugation steps as described in Kenkel \& Bay (2018). A check for the quality of the extracted DNA was performed on a $1 \%$ agarose gel. Reextraction of DNA was carried out on samples with low DNA quality, which is indicated by a faded band, or no band pattern appears on the agarose gel.

This study utilizes the whole ITS region (ITS1-5.8S-ITS2 region) of E. lamellosa rDNA to be amplified as a marker. A previous study conducted by Wijayanti et al. (2018) using a mtCOI marker on Acropora byacinthus populations resulted in accurate genetic identification, but less sensitivity to build a phylogenetic tree. A single copy of ITS (Internal Transcribed Spacer) region has been extensively used for population genetic and phylogenetic studies of corals and symbionts (see Takabayashi et al. 2003; Terrana et al. 2021). It has been reported that the rDNA ITS region has potentially become an accurate and sensitive marker to reveal the genetic diversity in the coral population, even with a small sample size (Afiq-Rosli et al. 2019). Amplification of the whole ITS region was carried out using forward primer ITS1F (5'-CT'TGTTCATTTAGAGGAAGTAA-3') and reverse primer ITS4 (5'-TCCTCCGCTTATTGATATGC-3') (Gardes \& Bruns 1993) by Integrated DNA Technology ${ }^{\mathrm{TM}}$. The reaction mixture contained $2 \mu \mathrm{L}$ of each primer, $12.5 \mu \mathrm{L}$ of Taq DNA Polymerase (MyTaqTM HS Red Mix, Bioline ${ }^{\circledR}$ ), $9 \mu$ Lof ddH2O (SuperPure nuclease-free water, BioScience ${ }^{\circledR}$ ), and $2 \mu \mathrm{L}$ of DNA template. The amplification was processed in the peqSTART Thermal Cycler (PEQLAB®) with the program set as follows: 1 cycle at $95^{\circ} \mathrm{C}(2 \mathrm{~min}) ; 35$ cycles at $94^{\circ} \mathrm{C}(45 \mathrm{~s}), 47^{\circ} \mathrm{C}(30 \mathrm{~s})$, and $72^{\circ} \mathrm{C}(1 \mathrm{~min})$. The amplicon quality was checked through electrophoresis on a $1 \%$ agarose gel and then visualized under a transilluminator. The high-quality amplicon appears as a clear and thick band. Only high-quality amplicons were sent for further sequencing to the 1st Base-Asia, Malaysia (http://www.baseasia.com). 
Data analysis

All sequences were analyzed further to confirm species identification of the coral samples genetically using BLAST (Basic Local Alignment Search Tool) features on NCBI (http:/ / ncbi.nlm.nih.gov). The chromatograph of each sequence was checked to verify and determine the base calling. ClustalW was used for sequence alignment. Sequences alignment and trimming were carried out in MEGA V.06 to generate a pairwise distance matrix and specific "fasta" formatted file (.fas) for downstream analysis. Molecular genetic diversity indices such as haplotype diversity and polymorphic site were obtained using DNAsp V5.10 (Librado \& Rozas 2009), with defaulted exclude gap or missing data sets. The population genetic diversity value range from 0 to 1 . Measurement of genetic differentiation was carried out using ARLEQUIN V3.5 (Excoffier \& Lischer 2010) with AMOVA (Analysis of Molecular Variance) test, as well as the genetic difference between the two populations (Fst and P-value). The significance covariance components were tested with 10,000 permutations.

The phylogenetic tree, genetic distance matrix, and population genetic network were constructed to determine the connectivity and relationship between samples. The Neighbor-joining tree $(\mathrm{NJ})$ was generated using MEGA V6.0 (Tamura et al. 2013) with Kimura 2-parameter and a bootstrap value of $1000 \times$ replication. The genetic pairwise distance was visualized in a similarity matrix using HeatMapper (https://heatmapper.ca) based on the Euclidean distance method. The POPart V1.7 (Leigh \& Bryant 2015) was used to implement automatically the unrooted minimum spanning network (MSN), while Network V1.0 was used for haplotype network analysis using the median-joining method (Bandelt et al. 1999).

\section{RESULTS}

Sequence identification and genetic structure

A total of 30 samples of E. lamellosa were successfully sequenced from both eastern- and western- populations with the length of sequences ranging from 701 to $728 \mathrm{bp}$. All sequences were genetically identified as E. lamellosa using BLAST features. The query cover value for all sequences is above $90 \%$ indicating all the nucleotides sequence in the samples is very similar to the GenBank data. The value of identification percentage for all sequences ranging from $88.87 \%$ to $98.68 \%$. The wide range of percentages may indicate a high genetic variation and the possible presence of unique sequences within populations that have not been registered in GenBank.

The topology of the Neighbor-Joining (NJ) tree divides the samples into 3 (three) clades (Figure 2). The NJ tree also shows a pattern of shared clades between the eastern and western groups. This indicated that there is close genetic connectivity between the two groups. Although both sequencing of GPE 33 and GPE 35 have the lowest identification percentage $(88.87 \%$ and $88.81 \%$, respectively), they still have very high query cover $(96 \%$ and $95 \%$, respectively). It suggests that these colonies were genetically unique. The phylogenetic tree reconstruction suggests to outgroup the GPE33 as the Clade C, while GPE35 remains within the Clade A (Figure 2). The phylogenetic tree was constructed based on NJ methods, including the downloaded GenBank sequence of Seriatopora hystrix was put as an outgroup. The use of the whole ITS region is feasible and very sensitive in representing small differences and mutations in E. lamellosa population. The ITS region also provides more robust data than any other genetic markers for coral, such as the mtCOI markers (Wijayanti et al. 2018). The Euclidean distance matrix also supports that colonies GPE 33 and GPE 35 are very distinct from other samples in both western and eastern groups (Figure 3). 


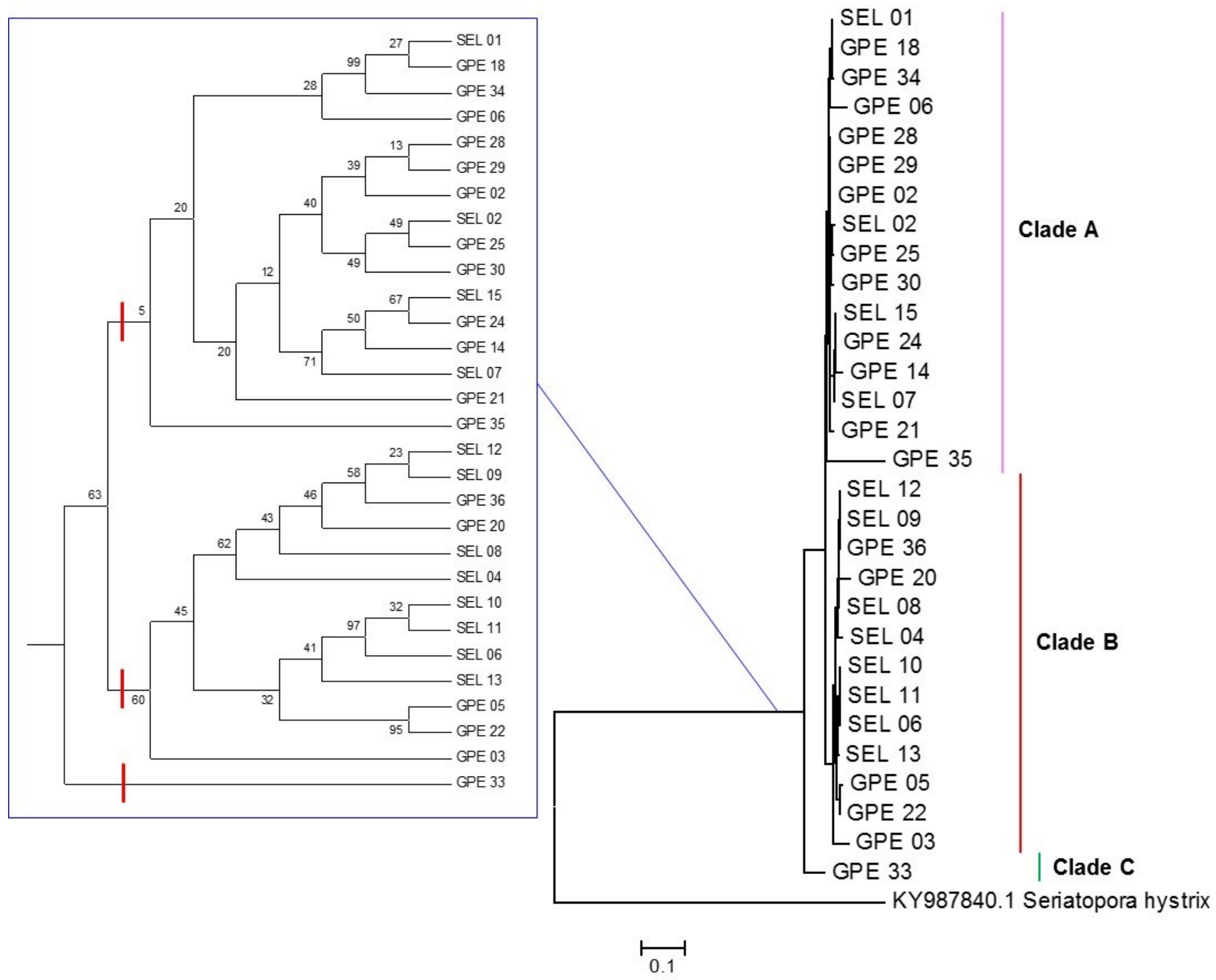

Figure 2. The phylogenetic tree represents the genetic structure of E. lamellosa from Lombok waters. This phylogenetic tree is detailed by a typology tree (inserted picture), showing 3 clades within the 2 geographic regions. Reconstruction of the phylogenetic tree only shows an indicative of coral clade variation based on ITS region, rather than a definitive means due to a lack of study on this species.

The heatmap distance matrix shows that there is a constrained flux of genes among the two populations. The genetic distance was lower than 0.144 within groups but moderate to high between groups ( $>0.144$ to 0.288 ) (Figure 3). However, there is an exception for both GPE 33 and GPE 35, which exhibits a very high difference value that close to 0.5759 against all colonies.

Genetic variation and demographic pattern

Both the eastern and western groups were in the same high haplotype diversity category. The eastern group had a slightly higher haplotype diversity value $(0.9804 ; \mathrm{n}=18)$ than the western group $(0.9394 ; \mathrm{n}=12)$. The trimming and cutting were carried out for all data set, resulting in the similar-sized 581 bp segment of the $5^{\prime}$ end of the obtained sequence from all individual samples. The comparison of those similar-sized sequences revealed 193 polymorphic sites. These polymorphic sites defined 23 haplotypes and 2 (two) of those haplotypes were shared between the eastern and western groups. A total of 19 haplotypes (63.33\% of the total sample) were unique and each consisted of only a single sample. The haplotype diversity for the 


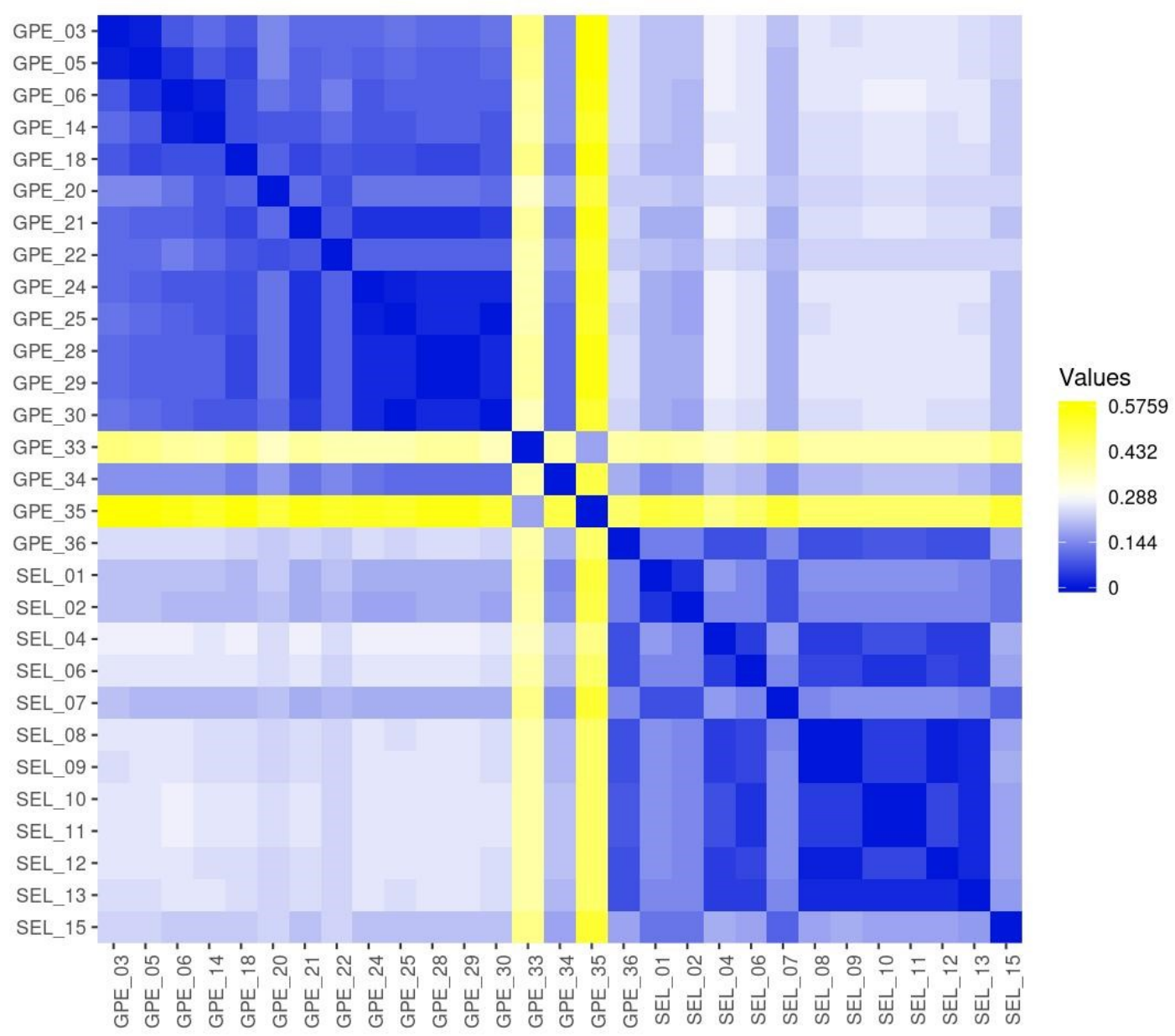

Figure 3. Pairwise distance matrix of Echinopora lamellosa colony visualized in a heatmap. Heatmap values show the differentiation scale.

entire E. lamellosa of Lombok waters (0.9770) were classified as very high diversity.

The network pattern analysis shows an indication of demographic expansion forming a large coral population. Both major clades (A and B) comprise both eastern and western colonies. This may suggest no obvious geographical differences in the distribution of haplotypes. Clade A consists of 13 haplotypes, clade B consists of 9 (nine) haplotypes, and clade $C$ comprises only a single haplotype belong to the eastern population. This population genetic structure is also supported by the minimum spanning network, which indicates a very close relationship among the three clades (Figure 4A). Minimum spanning network shows that the GPE02, which belongs to clade A and the eastern group, formed the center of a star-like network. Haplotype 1, which belongs to the eastern group, was put at the center of the haplotype network (Figure 4B). It suggests that the E. lamellosa from Lombok waters had experienced a demographic expansion. All network analysis confirms a possibility of genetic connectivity among all clades and haplotypes.

Despite the close genetic connectivity among all clades and haplotypes, AMOVA revealed a significant difference in population genetic between the two locations (Table 1). Genetic variation among groups was $7.76 \%$, but variation within a group was very high, reach up to $92.33 \%$. The fixation index (Fst) was 0.07667, which is classified in a low category (see Excoffier et al. 1992) and indicates a weak genetic relationship between the two populations. 


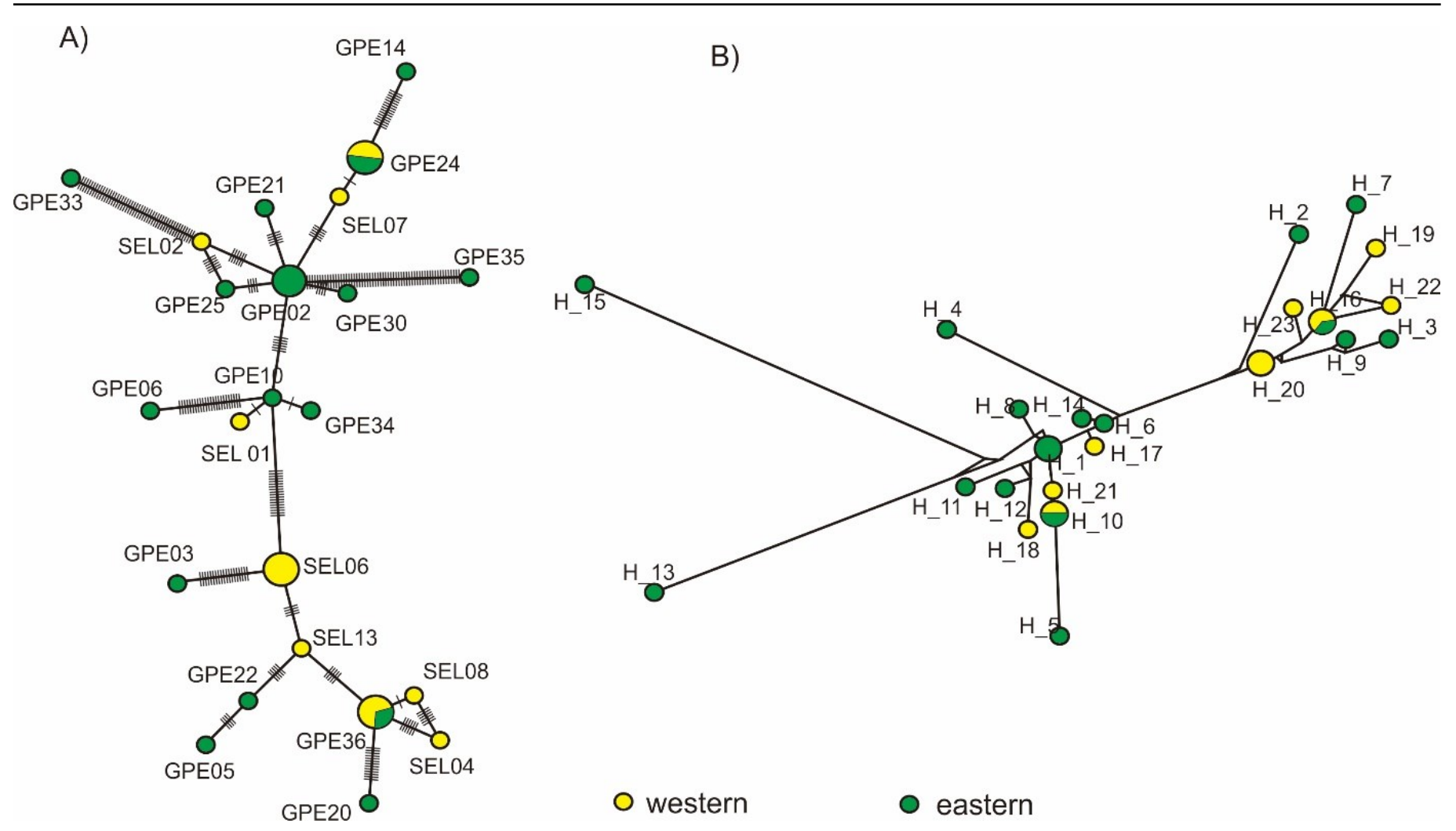

Figure 4. A) Unrooted minimum spanning network shows the genetic relationship among the population of E. lamellosa. B) Haplotype network illustrates the haplotype relationship within the E. lamellosa population.

Table 1. The AMOVA table revealed two different populations of the coral E. lamellose.

\begin{tabular}{lllll}
\hline Source of Variation & d.f. & Sum of Squares & Variation & Components \\
\hline Among group & 1 & 35.644 & $1.34794 \mathrm{Va}$ & $7.67 \%$ \\
Within-group & 28 & 454.556 & $16.23413 \mathrm{Vb}$ & $92.33 \%$ \\
Total & 29 & 490.200 & 17.58207 & $100 \%$ \\
\hline & & & Fst & 0.07667 \\
& & & P-value & $0.04985 \pm 0.00696$ \\
\hline
\end{tabular}

\section{DISCUSSION}

The present study revealed that the coral E. lamellosa in the western and eastern of Lombok waters are two different populations. This indicates that the geographical features separating the western and eastern waters of Lombok Island are a sufficient key barrier to their gene flow. This result supports a previous study by Nakajima et al. (2010), that corals within very close proximity could have small but significant genetic differences. Several studies suggest that in some cases, the geographical distance may not be correlated with the degree of genetic variation or divergence (Miller \& Ayre 2004; Magalon et al. 2005). Oceanographic conditions and coral reproduction type seem to be more crucial in determining the genetic diversity and connectivity (Hemond \& Vollmer 2010; Richards \& van Oppen 2012; Peluso et al. 2018), rather than geographical distance and spatial factors.

Both western and eastern populations of E. lamellosa have high haplotype diversity. Although there is no haplotype diversity data on the prebleaching population, such high haplotype diversity indicates that there are no selection processes that recently worked in both western and eastern coral populations. The present population of E. lamellosa is a mixture of old colonies and post-bleaching re-colonization. The coral E. lamellosa was 
recorded as one of the surviving species in the western population during the 2016 bleaching (Bachtiar et al. 2016). In the eastern population, coral bleaching in 2016 did not leave any noticeable impact when authors (IB and MIAG) dived to collect samples in 2018.

The present study also revealed that both western and eastern populations shared clades indicating the existence of gene flow between the two populations. Gene flow plays a major portion in determining the genetic distance of both intra- and inter-population. The Heatmap distance matrix shows that there is a restricted flux of genes between the two populations. Following genetic distance data, the AMOVA suggested a weak genetic relationship between the two populations. The genetic relationship between the two populations likely only occurs in the source reefs that supply planula larvae to both populations. The oceanographic condition of the two populations, which only have surface current from the Indonesian Throughflow (ITF), suggests that there are no source-sink interactions between the two populations. All ITF flow southward all year long in both the Lombok Strait (western population) and the Alas Strait (eastern population) (Sprintall et al. 2009).

Both coral populations are likely to be the sink of coral planula larvae drifted by the ITF from northern reefs in the Flores Sea or Makassar Strait. Previous studies suggest that the ITF contributed as the main transporter for larval dispersal across the coral triangle area. Bachtiar (2001b) reported similarity in spawning times between acroporid corals in Lombok Strait and Dampier Archipelago of Western Australia (Babcock et al. 1994) and hypothesized genetic connectivity from larval flow carried away in the ITF. More recent studies supported the hypothesis that acroporid corals in the Spermonde Islands (Makassar Strait) and Bolinao-Andara reef of the Western Philippines spawn at the same months as corals in the Lombok Strait (Yusuf et al. 2013; Gomez et al. 2018). Coral spawning in the Dampier Archipelago suggested that spawning synchrony is inherited from its ancestor in the tropical north (Babcock et al. 1994). Monismith et al. (2018) revealed that long-competence coral larvae may travel up to $1700 \mathrm{~km}$ in 100 days. Looking at the potential larval flow from northern reef sources, the recovery of both eastern and western groups was probably depending on the recolonization of larvae brought on by the ITF from common larval sources. This should explain why there were some common haplotypes (haplogroup) and clade variation shared between the two populations, with an expanded demographic trend. The post-settled corals then develop locally, resulting in restricted gene flow and differentiated populations geographically with the low genetic relationship among them.

The present study suggests that the two coral populations are mainly established from larval recolonization instead of the fragmentation of the surviving corals. The high genetic diversity values indicate the absence of the bottleneck effect. Such cases have been reported in the coral population of Seriatopora bystrix in the Flinders Reef (Noreen et al. 2009) and Porites lutea in the South China Sea (Huang et al. 2018). Both populations of E. lamellosa show higher genetic diversity values than other coral populations from Sulawesi waters and the eastern Lesser Sunda Islands (Jompa et al. 2020; Rosser et al. 2020). Several studies suggest that recolonization from longdistance source reefs contributes to relatively greater genetic diversity value in a recently established coral population (Starger et al. 2010; Aurelle et al. 2020; Smallhorn-West et al. 2020). The long-distance dispersal in corals can only be achieved by sexual reproduction with broadcast spawning mode.

Sexual reproduction improves genetic variation in a population through gene recombination between participating gametes. E. lamellosa is a hermaphrodite broadcast spawner (Petersen et al. 2007), but it has also a high 
potential to have asexual reproduction through clonal fragmentation. The coral E. lamellosa has a thin plate-form colony that can easily break off by physical forces from wave, anchors, or divers. It was expected therefore that many colonies of the population possibly generated from clonal fragmentation. This study revealed a very high overall haplotype diversity score that indicates a sexual reproduction mode was predominant in the recruitment mechanism (Boulay et al. 2012; Schweinsberg et al. 2017). It is also found that E. lamellosa from western and eastern populations were mostly consisting of unique genotypes with no clone identified in our dataset, which supports the prevalence contribution of sexual reproduction mode for both populations.

The present study rejected the hypothesis stated in the introduction that there is an association between coral genetic diversity and its bleaching resistance. Coral genetic diversity cannot explain the resistance of the coral E. lamellosa in Lombok waters. The haplotype diversity between the two populations is only slightly different (0.9804 versus 0.9394$)$. It is not very convincing therefore that such a small difference solely results in the ecological difference in coping with thermal stress. In a previous study, the algal symbiont of the two populations of E. lamellosa neither provide any explanation about the coral resistance to bleaching (Bachtiar et al. 2019), although algal symbiont has been reported by many authors to affect coral resistance to bleaching (Wall et al. 2020). Bachtiar et al. (2019) found that the algal symbiont of the corals in the eastern population consists of clade $\mathrm{B}$ and $\mathrm{C}$, while the western population only has clade $\mathrm{C}$ symbiont. Both clades B and C symbionts are non-resistant to bleaching. Loram et al. (2007) reported that the clade B symbiont only provides minor physiological benefits that may aid in their host survival. Neither diversity of coral nor its symbiont has an association with the resistance of E. lamellosa to coral bleaching. Likely, the survival of coral E. lamellosa in Lombok may not depend on the existence of adaptive symbionts but rather depends on the other environmental factors.

The environmental setting may explain the resistance of E. lamellosa in the eastern population, but not in the western population. Both populations have different environmental complexities with the eastern population have an advantage, that likely serves as coral refugia. Gili Petagan in Eastern Lombok waters is a key entirely covered by mangroves and surrounded by two other mangrove-covered keys, Gili Sulat and Gili Lawang. High survivability of corals are often found within or close to coastal vegetation, such as mangrove forest or vast seagrass bed (Camp et al. 2016; Lord et al. 2020). Mangrove vegetation not only exports litter to its adjacent ecosystems but also disperse dissolved tannin (López-Portillo et al. 2017; Stewart et al. 2021). The dissolved tannin and other chromophoric dissolved organic matter (CDOM) derived from marine plants may protect corals under the stress of water temperature from excessive ultraviolet radiation (UV-R) exposure and act as a pH buffer during the bleaching (Kellogg et al. 2020). Such a mechanism may provide coral refugia that increase coral survival from bleaching. In contrast, coral in the Gili Anyaran of the western population is about $7 \mathrm{~km}$ away from the mangrove area, and $5 \mathrm{~km}$ from seagrass beds.

The resistance to bleaching of the coral E. lamellosa is likely related to its holobiont and trophic strategy. Coral E. lamellosa has been reported as moderately susceptible to bleaching, in the Great Barrier Reefs (Marshall \& Baird 2000). Recent studies are accumulating to see the importance of the coral holobiont to the physiology of the coral, including its thermal stress tolerance (Boilard et al. 2020). Holobiont is a consortium of coral, algal symbiont, and microbiota. The microbiota is composed of prokaryotes, eukaryotes, and viruses. Coral susceptibility to bleaching is dependent on the robustness of the complex mutual relationship within the coral holobiont 
(Bourne et al. 2016; Boilard et al. 2020). Coral trophic strategy may also explain the resistance of E. lamellosa. Corals may be autotrophic, heterotrophic, or mixotrophic. Conti-Jerpe et al. (2020) showed that autotrophic corals are more vulnerable to bleaching than heterotrophic corals. So far, there is no information about the trophic strategy of the coral E. lamellosa. Future studies should address the trophic strategy to obtain a more practical assessment method to determine the resistance of coral taxa to bleaching.

\section{CONCLUSION}

In conclusion, neither coral- nor symbiont- genetic diversity may explain the resistance of the coral E. lamellosa to bleaching. The genetic of E. lamellosa showed high diversity at either western or eastern Lombok waters.

Population genetic connectivity between them may occur at the larval source. The two populations both survived well from the 2016 coral bleaching, regardless they have $\mathrm{B}$ and $\mathrm{C}$ clades symbiont. Both populations likely achieve their resistance to bleaching by adopting a robust holobiont or suitable trophic strategy.

\section{AUTHORS CONTRIBUTION}

I.B. designed the study. M.I.A.G. carried out the laboratory work. I.R. and B.H.A. analyzed the data. I.B. and M.I.A.G. collected samples and wrote the manuscript. All authors read and approved the final version of the manuscript.

\section{ACKNOWLEDGMENTS}

This study was supported by USAID through Sustainable Higher Education Research Alliances (SHERA) Program - Center for Collaborative Research Animal Biotechnology and Coral Reef Fisheries (CCR ANBIOCORE). Thanks to Anugrah Aprian Ademullah who assists us in field data collection, and also thanks to Dr. Hawis H. Maduppa who provided facilities and support in Laboratorium Biosistematika dan Biodiversitas, IPB. We also express our gratitude to the local government for the permit and favors during the fieldwork. Fieldwork assistances also came from UKM Riset Kelautan dan Perikanan, Universitas Mataram.

\section{CONFLICT OF INTEREST}

The authors declare that they do not competing for interest to submit the manuscript to the Journal of Tropical Biodiversity and Biotechnology (JTBB).

\section{REFERENCES}

Afiq-Rosli, L. et al., 2019. Maximising genetic diversity during coral transplantation from a highly impacted source reef. Conservation Genetics, 20(3), pp.629-637.

Aurelle, D. et al., 2020. Genetic insights into recolonization processes of Mediterranean octocorals. Marine Biology, 167(73).

Babcock, R.C. et al., 1994. Mass spawning of corals on a high latitude coral reef. Coral Reefs, 13, pp.161-169.

Bachtiar, I., 2001a. Promoting recruitment of scleractinian corals using artificial substrate in the Gill Indah, Lombok Barat, Indonesia. Proceeding 9th International Coral Reef Symposium Bali, 1, pp.425-430.

Bachtiar, I., 2001b. Reproduction of three scleractinian corals (Acropora cytherea, A. nobilis, Hydnophora rigida) in eastern Lombok Strait, Indonesia. Ilmu Kelautan, 21, pp.18-27. 
Bachtiar, I. et al., 2016. Monitoring of Coral Reef Health and Related Ecosystems in Sekotong, Lombok Barat (in Indonesian language). Technical Report for COREMAP-CTI. Jakarta: Lembaga Ilmu Pengetahuan Indonesia. p.95.

Bachtiar, I. \& Hadi, T.A., 2019. Differential impacts of 2016 coral bleaching on coral reef benthic communities at the Sekotong Bay, Lombok Barat, Indonesia. Biodiversitas, 20(2), pp.570-575.

Bachtiar, I. et al., 2019. Coral Echinopora lamellosa hosts multiple clades of symbionts in western Alas Strait, Indonesia. AIP Conference Proceedings, 2199, 070013.

Bandelt, H.J. et al., 1999. Median-joining networks for inferring intraspecific phylogenies. Molecular Biology and Evolution, 16(1), pp.37-48.

Boilard, A. et al., 2020. Defining coral bleaching as a microbial dysbiosis within the coral holobiont. Microorganisms, 8(11), 1682.

Boulay, J.N. et al., 2012. High genotypic diversity of the reef-building coral Porites lobata (Scleractinia: Poritidae) in Isla del Coco National Park, Costa Rica. Revista de Biología Tropical, 60(3), pp.279-292.

Bourne, D.G. et al., 2016. Insights into the coral microbiome: Underpinning the health and resilience of reef ecosystems. Annual Review of Microbiology, 70, pp.317-340.

Brown, B.E. \& Suharsono, 1990. Damage and recovery of coral reefs affected by El Niño related seawater warming in the Thousand Islands, Indonesia. Coral Reefs, 8, pp.163-170.

Buddemeier, R.W. \& Fautin, D.G., 1993. Coral bleaching as an adaptive mechanism: A testable hypothesis. BioScience, 43(5), pp.320-326.

Camp, E.F. et al., 2016. Mangrove and seagrass beds provide different biogeochemical services for corals threatened by climate change. Frontiers in Marine Science, 3, 52.

Conti-Jerpe, I.E. et al., 2020. Trophic strategy and bleaching resistance in reef -building corals. Science Advances, 6(15), eaaz5443.

Cooke, I. et al., 2020. Genomic signatures in the coral holobiont reveal host adaptations driven by Holocene climate change and reef specific symbionts. Science Advances, 6(48), eabc6318.

Excoffier, L. \& Lischer, H.L.L., 2010. Arlequin suite ver 3.5: a new series of programs to perform population genetics analyses under Linux and Windows. Molecular Ecology Resources, 10(3), pp.564-567.

Excoffier, L. et al., 1992. Analysis of molecular variance inferred from metric distances among DNA haplotypes: Application to human mitochondrial DNA restriction data. Genetics, 131(2), pp.479-491.

Fuller, Z.L. et al., 2020. Population genetics of the coral Acropora millepora: Toward genomic prediction of bleaching. Science, 369(6501), eaba4674.

Gardes, M. \& Bruns, T.D., 1993. ITS primers with enhanced specificity for Basidiomycetes - Application to the identification of mycorrhizae and rusts. Molecular Ecology, 2(2), pp.113-118.

Gomez, E. J. et al., 2018. Gametogenesis and reproductive pattern of the reef -building coral Acropora millepora in northwestern Philippines. Invertebrate Reproduction \& Development, 62(4), pp.202-208.

Hemond, E.M. \& Vollmer, S.V., 2010. Genetic diversity and connectivity in the threatened staghorn coral (Acropora cervicomis) in Florida. PLos One, 5(1), e8652.

Huang, W. et al., 2018. Genetic diversity and large-scale connectivity of the scleractinian coral Porites lutea in the South China Sea. Coral Reefs, 37(4), pp.1259-1271.

Hughes, T.P. et al., 2018. Spatial and temporal patterns of mass bleaching of corals in the Anthropocene. Science, 359(6371), pp.80-83. 
Jompa, J. et al., 2020. Genetic patterns of the corals Euphyllia glabrescens and Lobophyllia corymbosa across the Indonesian Archipelago. Biodiversitas, 21 (6), pp.2492-2499.

Kellogg, C.A. et al., 2020. Identifying mangrove-coral habitats in the Florida Keys. PeerJ, 8(1), e9776.

Kenkel, C.D. \& Bay, L.K., 2018. Exploring mechanisms that affect coral cooperation: Symbiont transmission mode, cell density and community composition. PeerJ, 6(1648), e6047.

Leigh, J.W. \& Bryant, D., 2015. PopART: Full-feature software for haplotype network construction. Methods in Ecology and Evolution, 6(9), pp.11101116.

Librado, P. \& Rozas, J., 2009. DnaSP v5: A software for comprehensive analysis of DNA polymorphism data. Bioinformatics, 25(11), pp.14511452.

López-Portillo, J. et al., 2017. Water quality and mangrove-derived tannins in four coastal lagoons from the Gulf of Mexico with variable hydrologic dynamics. Journal of Coastal Research, 77, pp.28-38.

Loram, J.E. et al., 2007. Molecular quantification of symbiotic dinoflagellate algae of the genus Symbiodinium. The Biological Bulletin, 21(3), pp.259-268.

Lord, S.C. et al., 2020. Multi-year viability of a reef coral population living on mangrove roots suggests an important role for mangroves in the broader habitat mosaic of corals. Frontiers in Marine Science, 7, p.377.

Magalon, H., Adjeroud, M. \& Veuille, M., 2005. Patterns of genetic variation do not correlate with geographical distance in the reef-building coral Pocillopora meandrina in the South Pacific. Molecular Ecology, 14(7), pp.1861-1868.

Marshall, P.A. \& Baird, A.H., 2000. Bleaching of corals on the Great Barrier Reef: Differential susceptibilities among taxa. Coral Reefs, 19(2), pp.155163.

Miller, K.J. \& Ayre, D.J., 2004. The role of sexual and asexual reproduction in structuring high latitude populations of the reef coral Pocillopora damicomis. Heredity, 92, pp.557-568.

Monismith, S.G. et al., 2018. Transport between Palau and the Eastern Coral Triangle: Larval connectivity or near misses. Geophysical Research Letters, 45(10), pp.4974-4981.

Morikawa, M.K. \& Palumbi, S.R., 2019. Using naturally occurring climate resilient corals to construct bleaching-resistant nurseries. Proceedings of the National Academy of Sciences of the United States of America, 116(21), pp.10586-10591.

Nakajima, Y. et al., 2010. Gene flow and genetic diversity of a broadcastspawning coral in northern peripheral populations. PLos One, 5(6), e11149.

Noreen, A.M. et al., 2009. Genetic diversity and connectivity in a brooding reef coral at the limit of its distribution. Proceedings of the Royal Society B: Biological Sciences, 276(1675), pp.3927-3935.

Peixoto, R.S. et al., 2017. Beneficial microorganisms for corals (BMC): Proposed mechanisms for coral health and resilience. Frontiers in Microbiology, 8, 341.

Peluso, L. et al., 2018. Contemporary and historical oceanographic processes explain genetic connectivity in a Southwestern Atlantic coral. Scientific Reports, 8, 2684.

Petersen, D. et al., 2007. Sexual reproduction of scleractinian corals in public aquariums: current status and future perspectives. International Zoo Yearbook, 41(1), pp.122-137.

Richards, Z.T. \& van Oppen, M.J., 2012. Rarity and genetic diversity in Indo -Pacific Acropora corals. Ecology and Evolution, 2(8), pp.1867-1888. 
Rosser, N.L. et al., 2020. Geography and spawning season drive genetic divergence among populations of the hard coral Acropora tenuis from Indonesia and Western Australia. Coral Reefs, 39(1), pp.989-999.

Schweinsberg, M. et al., 2017. Inter-and intra-colonial genotypic diversity in hermatypic hydrozoans of the family Milleporidae. Marine Ecology, 38(1), e12388.

Smallhorn-West, P.F. et al., 2020. Coral reef annihilation, persistence and recovery at Earth's youngest volcanic island. Coral Reefs, 39, pp.529_ 536.

Sprintall, J. et al., 2009. Direct estimates of the Indonesian Throughflow entering the Indian Ocean: 2004-2006. Journal of Geophysical Research, 114 (C7), C07001.

Starger, C.J. et al., 2010. The recovery of coral genetic diversity in the Sunda Strait following the 1883 eruption of Krakatau. Coral Reefs, 29(3), pp.547-565.

Stewart, H.A. et al., 2021. Caribbean mangrove forests act as coral refugia by reducing light stress and increasing coral richness. Ecosphere, 12(3), e03413.

Swain, T.D. et al., 2021. A phylogeny-informed analysis of the global coralsymbiodiniaceae interaction network reveals that traits correlated with thermal bleaching are specific to symbiont transmission mode. mSystems, 6(3), e00266-21.

Takabayashi, M. et al., 2003. Genetic variation of the scleractinian coral Stylophora pistillata from western Pacific reefs. Coral Reefs, 22(1), pp.1722.

Tamura, K. et al., 2013. MEGA6: Molecular Evolutionary Genetics Analysis Version 6.0. Molecular Biology and Evolution, 30(12), pp.2725-2729.

Terrana, L. et al., 2021. ITS1 variation among Stichopathes cf. maldivensis (Hexacorallia: Antipatharia) whip black corals unveils conspecificity and population connectivity at local and global scales across the IndoPacific. Coral Reefs, 40(1), pp.521-533.

Wall, C.B. et al., 2020. Divergent symbiont communities determine the physiology and nutrition of a reef coral across a light-availability gradient. The ISME Journal, 14, pp.945-958.

Wijayanti, D.P. et al., 2018. Molecular identification and genetic diversity of Acropora hyacinthus from Boo and Deer Island, Raja Ampat, West Papua. IOP Conference Series: Earth and Environmental Science, 116, 012065.

Yusuf, S. et al., 2013. Reproduction pattern and multispecific spawning of Acopora spp. in Spermonde Islands reefs, Indonesia. Ilmu Kelautan: Indonesian Journal of Marine Sciences, 18, pp.172-178.

Zamani, N.P. et al., 2019. The intracellular photopigment and glutathione (GSH) dynamics in symbiodinium natural population during light stress and recovery. IOP Conference Series: Earth and Environmental Science, 325, 012015. 